\title{
THE WEIGHT OF THE VENTRICLES IN THE LATER WEEKS OF INTRA-UTERINE LIFE
}

BY

\author{
JOHN L. EMERY AND M. S. MACDONALD
}

From the Department of Pathology, The Children's Hospital, Sheffield

Received December 17, 1959

In 1883 Muller published a survey of heart weights of fœtuses, children of different ages, and adults, and his values have been the standard reference for over half a century (Brock, 1932). Muller's series included 61 stillborn babies ranging in size from $100 \mathrm{~g}$. body weight to $3000 \mathrm{~g}$. In his two groups that include infants with a body weight of 100-1000 g., he shows a low R.V./L.V. weight ratio with the left ventricle heavier than the right in three of the four readings for these age groups. The R.V./L.V. weight ratio became greater than unity in his heaviest group of fœtuses (i.e. those weighing $3000 \mathrm{~g}$. and more). Muller's method of dissection has since been questioned (Dull, 1941; Hort, 1955) because he weighed the free ventricle wall and the septum separately. He divided the weight of the septum in the constant proportion 30 per cent to the right side and 70 per cent to the left. This gives an erroneous impression of right and left ventricular weights as the proportion of each ventricle taking part in the formation of the septum alters with the relative sizes of the cavities (Fig. 1).

Smith (1928-9) published the total heart weights related to body weight of 28 premature infants, but did not give their periods of gestation. In 1933, Blackfan stated that the right ventricle weighed 13 per cent more than the left in the newborn: he found the combined ventricular weight to be $15 \mathrm{~g}$. in a $20 \mathrm{-g}$. heart, of which the right constituted $8 \mathrm{~g}$. and the left $7 \mathrm{~g}$.

Merkel and Witt (1955) dissected the hearts of 267 fotuses by Muller's method and related the ventricle weights to body weight. They do not give any tables of figures but only a graph of mean lines, suggesting that until the fotuses have reached a body weight of $1800 \mathrm{~g}$. the left ventricle is slightly heavier than the right: at this body weight level the two ventricular growth curves cross and the right becomes progressively heavier than the left. Their weights differ from Muller's in that in his series the right ventricle was heavier than the left when the body weight was $1000 \mathrm{~g}$. or more.

Keen (1955) in his study of children's hearts excluded premature infants from his main series and he did not know their gestation ages. Pansinello et al. (1958) dissected 25 premature and 8 full-term infant's hearts, and divided the muscle of the interventricular septum longitudinally in order to obtain values for the right and left ventricular weights: they found that the left ventricular weight was significantly higher than the right.

The method of dissection of the hearts used by Muller and by Meckel and Witt, which involved the assignment of a constant proportion of the septum to each ventricle, leaves much to be desired. Further, the clinical difficulties in assessing the gestation age of a stillborn child, the differences in water and blood content of the infant at birth, and the effect of intra-uterine disease on the nutrition of the infant make body weight alone an inadequate measure. Ventricular weights related to crown-rump length, which is probably the most reliable single measurement of a newborn child, 


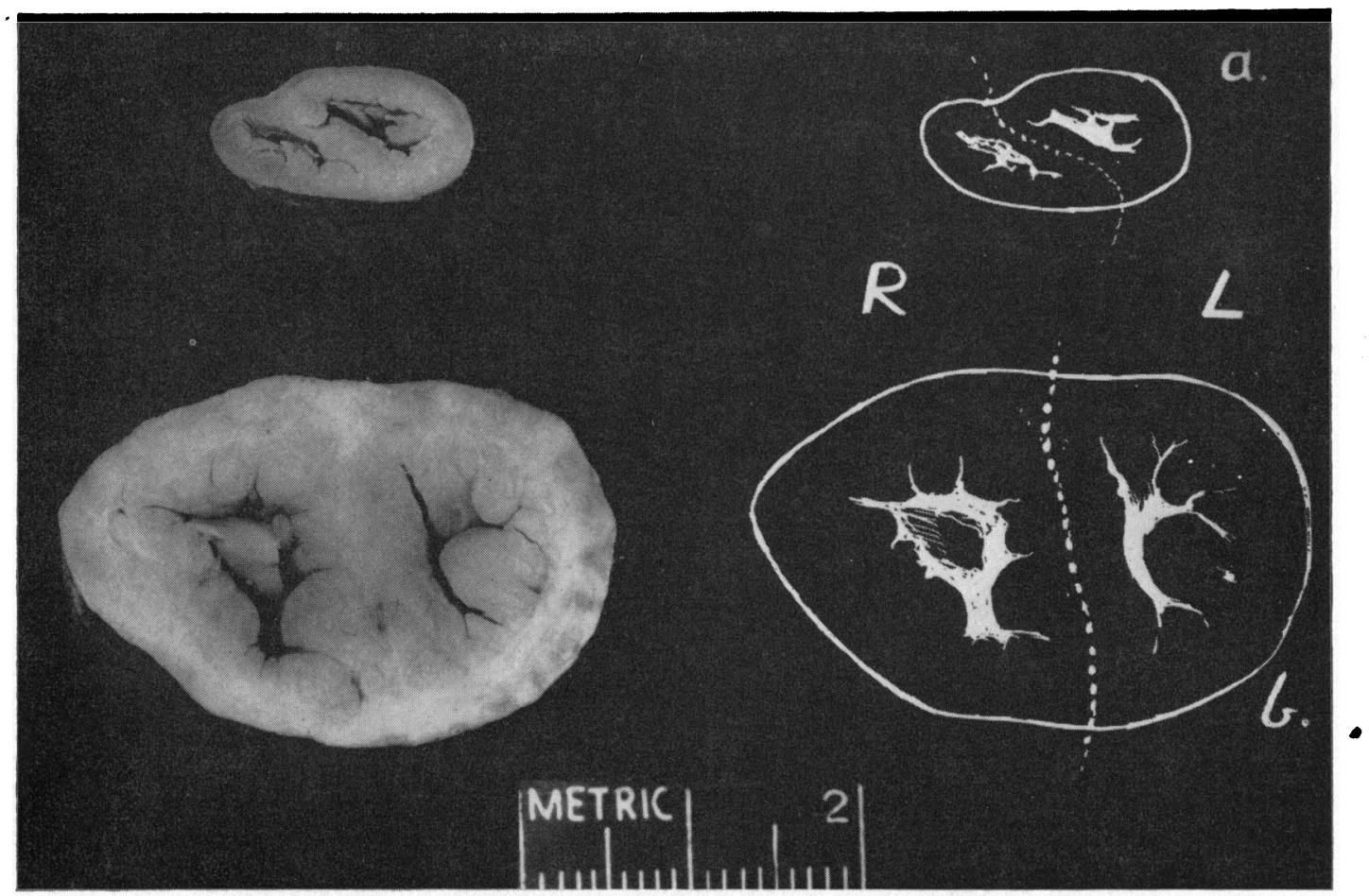

FIG. 1.-Cross-sections of heart from a fœtus of 32 weeks and a fœtus of 36 weeks maturity, taken at comparable levels across the ventricles. The dotted lines on the diagrams on the right indicate the line at which the ventricles would be divided for the purpose of weighing.

do not seem to be available. The present survey attempts to assess the left and right heart ventricular weights in "normal" stillborn hearts related to the age of the child, sitting height, i.e. crownrump length, and to the gestation age, and to assess the individual and relative growth of the ventricles up to the time of birth, related to those three general criteria.

\section{Material AND Method}

The hearts were obtained from post-mortem examinations carried out by the staff of the department of Pathology of the Children's Hospital, Sheffield, and many, by the courtesy of Dr. A. J. N. Warrack, at the City General and Nether Edge Hospitals, Sheffield.

At necropsy the cavities of the heart were opened only sufficiently to remove blood clots and to exclude gross deformities. The hearts were fixed still attached to the other thoracic viscera. No heart.showing any recognized abnormality, or from a child showing any gross developmental abnormality in any other organs was used, the necropsies being carried out by, or all organs seen by a pathologist with experience of over 3000 such dissections. The material presented here comes from a much larger mass of material concerned with a number of aspects of the developing heart. The present cases were 155 consecutive stillbirths, with periods of gestation calculated on the basis of last menstrual period from 24 to 44 weeks.

The hearts were separated from the lungs, and together with the great vessels placed in pots containing the necropsy number, and at the time of later detailed dissection it was not known whether the infant had been stillborn or liveborn, and no other organs, notably lungs, were available for inspection. 
The hearts were removed from the formalin and washed in tap water to remove all small blood clots. The parietal pericardium was discarded. The venæ cavæ and pulmonary veins were cut off at their junctions with the atria and the two atria were separately dissected off the ventricles. The aorta and pulmonary artery were then cut off immediately below the level of their valves. The two ventricles were cut transversely in a series of slices each about $0.5 \mathrm{~cm}$. thick. The two ventricles were separated from each other by dividing the septum along what appeared to be a natural line of cleavage as shown by the dotted line in Fig. 1. Excess moisture was blotted off, and the pieces were left for a while in a cool closed chamber, having water at the bottom in an attempt to stabilize the water content, and the right and left ventricular pieces were weighed separately on a laboratory balance, the weights being corrected to the nearest $0 \cdot 1 \mathrm{~g}$.

Each case had its own working sheet on which the weights were recorded. Later, the age of the child, crown-rump length, body weight, cause of death, and a note on the lung histology were added. Twenty-five stillborn hearts were discarded because of other congenital abnormalities in the child, although the hearts showed no abnormalities.

The analysis of the results was carried out in the same way for each growth factor and that against gestation age is described here as an example. The cases were divided by four-week intervals into five groups spanning gestation ages of 24 to 44 weeks. The number of cases in each group was determined (n) and the arithmetic means of right ventricular weight, left ventricular weight, and L.V./R.V. weight ratio and their standard deviations $(\sigma)$ calculated. The limits of trustworthiness of each of the means was then calculated according to the formula: $\pm \frac{2}{3} \sqrt{\frac{\sigma}{n}}$

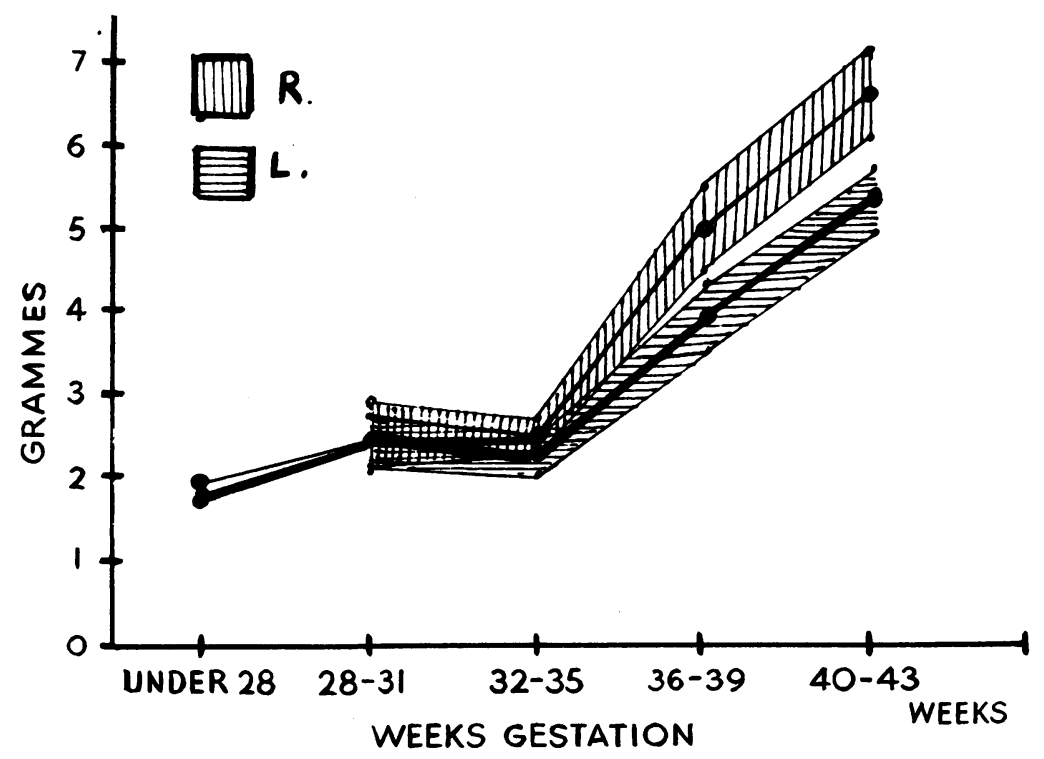

FIG. 2.-Graph showing the mean right and left ventricular weights with their limits of trustworthiness against gestation age.

\section{RESULTS}

Analysis by Gestation Age: 126 cases, Fig. 2 and 3. The cases were subdivided in four-week intervals into five groups spanning an age range of 24 to 44 weeks gestation. The values obtained were as follows: five children of under 28 weeks gestation, L.V. mean, $1 \cdot 12$ g., R.V. $1 \cdot 8 ; 19$ children between 28 and 31 weeks, L.V. $2 \cdot 5(\sigma 1 \cdot 19)$, R.V. $2 \cdot 5(\sigma 1 \cdot 43) ; 28$ infants from 32 to 35 weeks, L.V. 


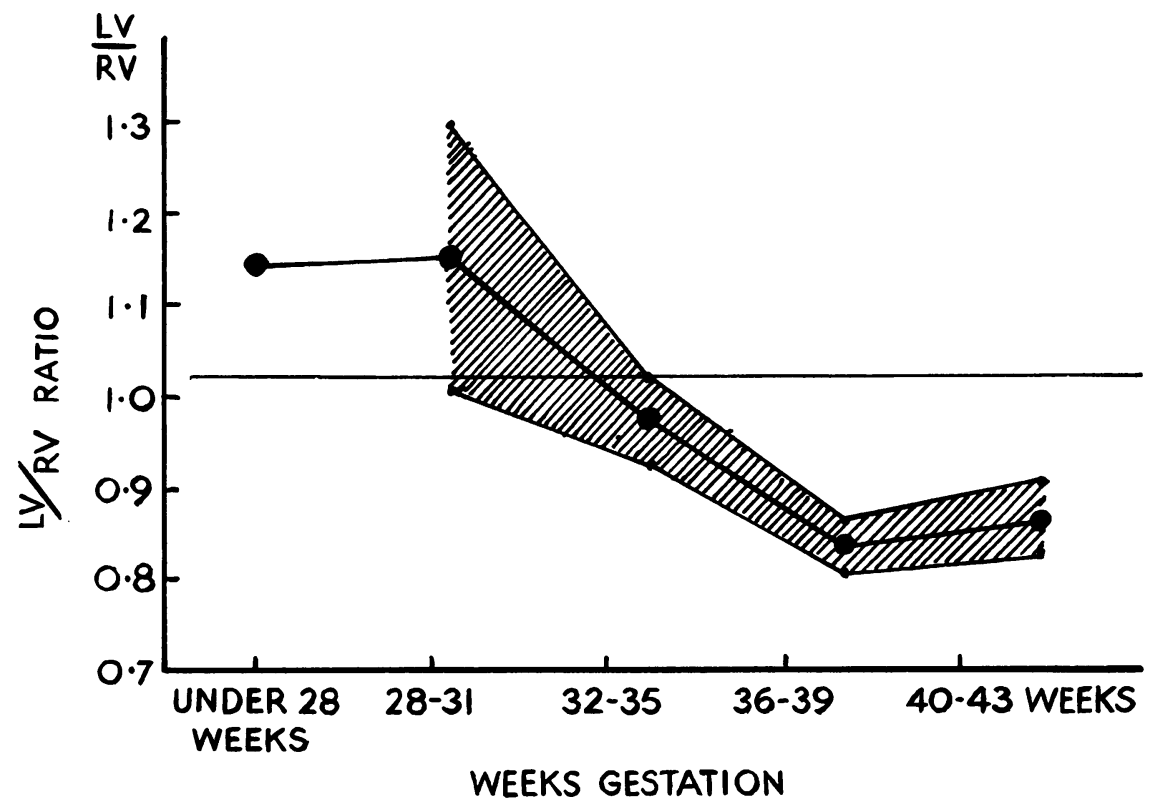

FIG. 3.-Graph showing the mean L.V./R.V. weight ratios with their limits of trustworthiness against gestation age.

$2.5(\sigma 0.9)$, R.V. $2.5(\sigma 0 \cdot 88) ; 42$ infants from 36 to 39 weeks, L.V. $4.0(\sigma 1 \cdot 8)$, R.V. 5.0 ( $\sigma 2.5)$; and 32 infants of between 40 and 43 weeks, L.V. $5 \cdot 5(\sigma$ 1.67), R.V. $6 \cdot 7(\sigma 2 \cdot 0)$.

In infants of gestation less than 32 weeks the right and left ventricular weights are almost equal, being 1.8 and $1.9 \mathrm{~g}$. respectively; but from this time onwards the right ventricle gains weight more rapidly than the left until, by the 36 th -40 th week group, its weight is $5.0 \mathrm{~g}$. compared with $4.0 \mathrm{~g}$. for the left ventricle. In the infants of gestation 40-44 weeks there is apparently a slight deceleration of right ventricular growth. Left ventricular increase has continued as before and the mean absolute right and left ventricular weights in these most mature infants are $6.7 \mathrm{~g}$. and $5.5 \mathrm{~g}$. respectively.

The trends shown in the absolute weight curve are reflected in the weight-ratio graph. The ratio L.V./R.V. weight is greater than unity before the 31 st week of gestation. Thereafter the more rapid weight gain of the right ventricle is reflected in a steep fall in the weight ratio which by 35 weeks has become less than 1 . The fall continues until at 39 weeks it has reached 0.8 after which there is a slight rise in the mean ratio to a value of 0.85 in the gestation age group 40-44 weeks.

Analysis by Crown-Rump Length, 103 cases, Fig. 4 and 5. The cases were subdivided in intervals of $5 \mathrm{~cm}$. into four crown-rump length groups over a range of $20-40 \mathrm{~cm}$. The values obtained were as follows: 9 children, crown-rump length of 20-24.5 cm.: L.V. 1.4, R.V. 1.6; 20 children of C.R. length $25-29.5 \mathrm{~cm} .:$ L.V. $2 \cdot 4(\sigma 0.68)$, R.V. $2.6(\sigma 0.58) ; 45$ children of C.R. length $30-34.5 \mathrm{~cm}$. : L.V. $3.7(\sigma 1.25)$, R.V. $4.4(\sigma 2.04)$; and 29 children of C.R. length 35-39.5 cm.: L.V. $5.9(\sigma 1 \cdot 37)$, R.V. $7 \cdot 3(\sigma$ 2.35).

The weight curves (Fig. 4) show practically equal values for the two ventricles in the two smallest groups of fœtuses and they gain weight at equal rates. After a crown-rump length of $29 \mathrm{~cm}$. the growth curves diverge and from 30 weeks onwards there is no overlap of the limits of trustworthiness of the mean weight of the two ventricles.

The L.V./R.V. weight ratio curve (Fig. 5) shows a mean value of nearly 1.3 in the smallest infants and the lower limit is above 1. Between this group of cases and the next there is a steep fall in the ratio, bringing it below 1 . It continues to fall less steeply to reach a value of 0.83 in infants of crown-rump length $35-40 \mathrm{~cm}$. 


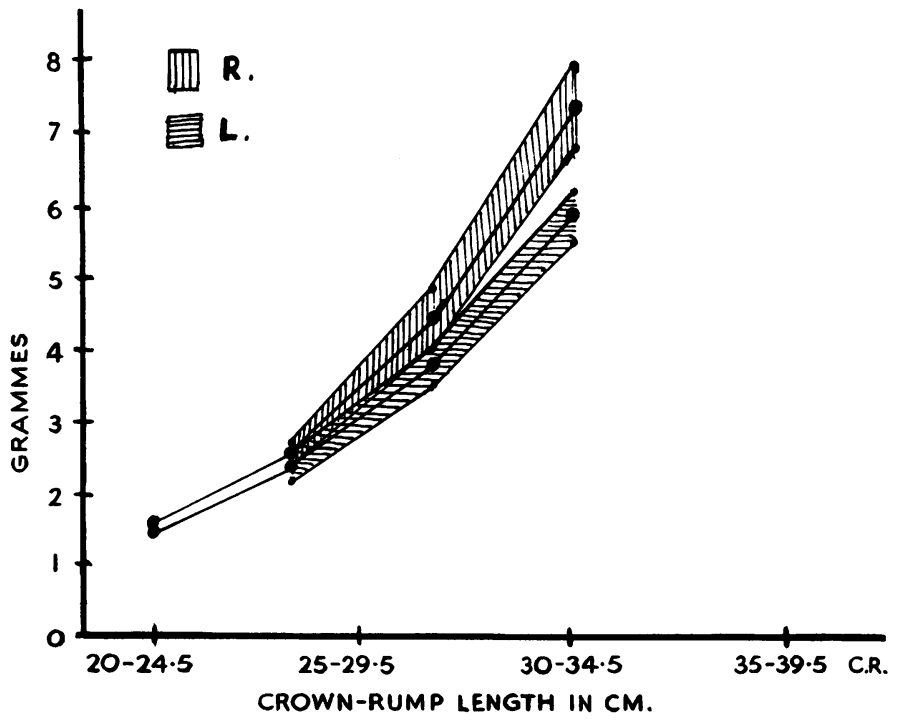

FIG. 4.-Graph showing the mean right and left ventricular weights with their limits of trustworthiness, against crown-rump length.

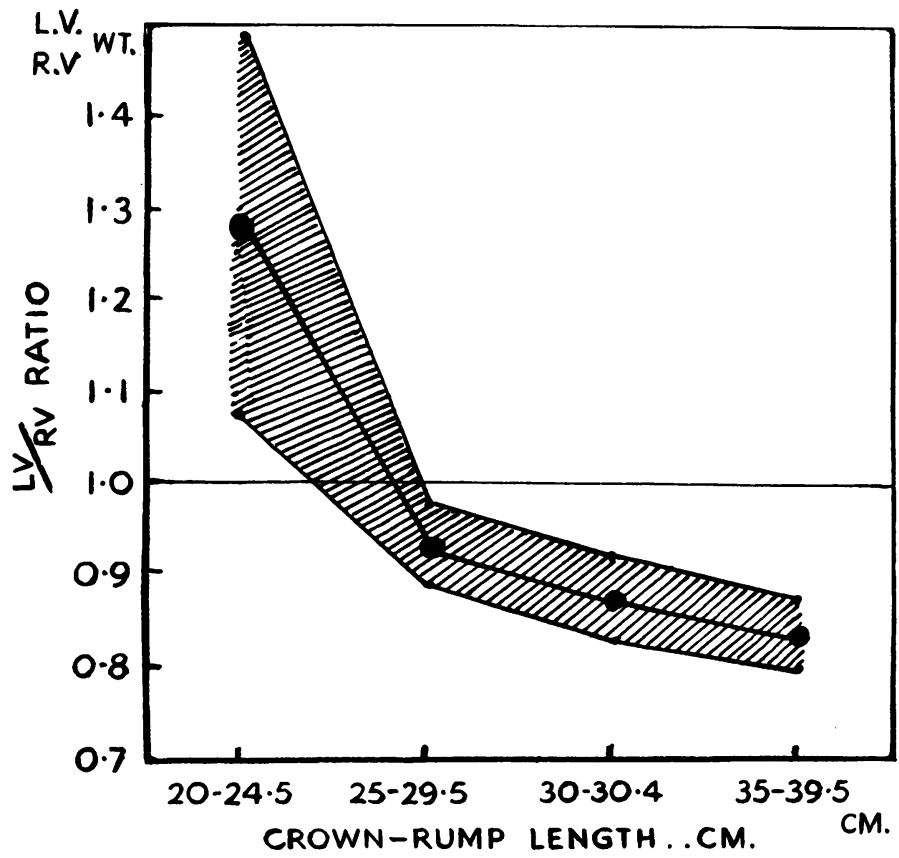

Fig. 5.-Graph showing the mean L.V./R.V. ratios with their limits of trustworthiness against crown-rump length.

There is a relative flattening in the ventricular weight ratio curve, towards normal "term" but there is no reversal of the falling trend between the two most mature groups of infants.

Analysis by Body Weight, 78 cases, Fig. 6 and 7. The cases are divided in 500-g. steps into body weight groups over a range of 500 to $4000 \mathrm{~g}$. The values obtained were as follows: 9 children of body weight 500-999 g., L.V. 1.5 ( $\sigma 0.45)$, R.V. 1.4; 14 children of body weight 1000-1499 g., 


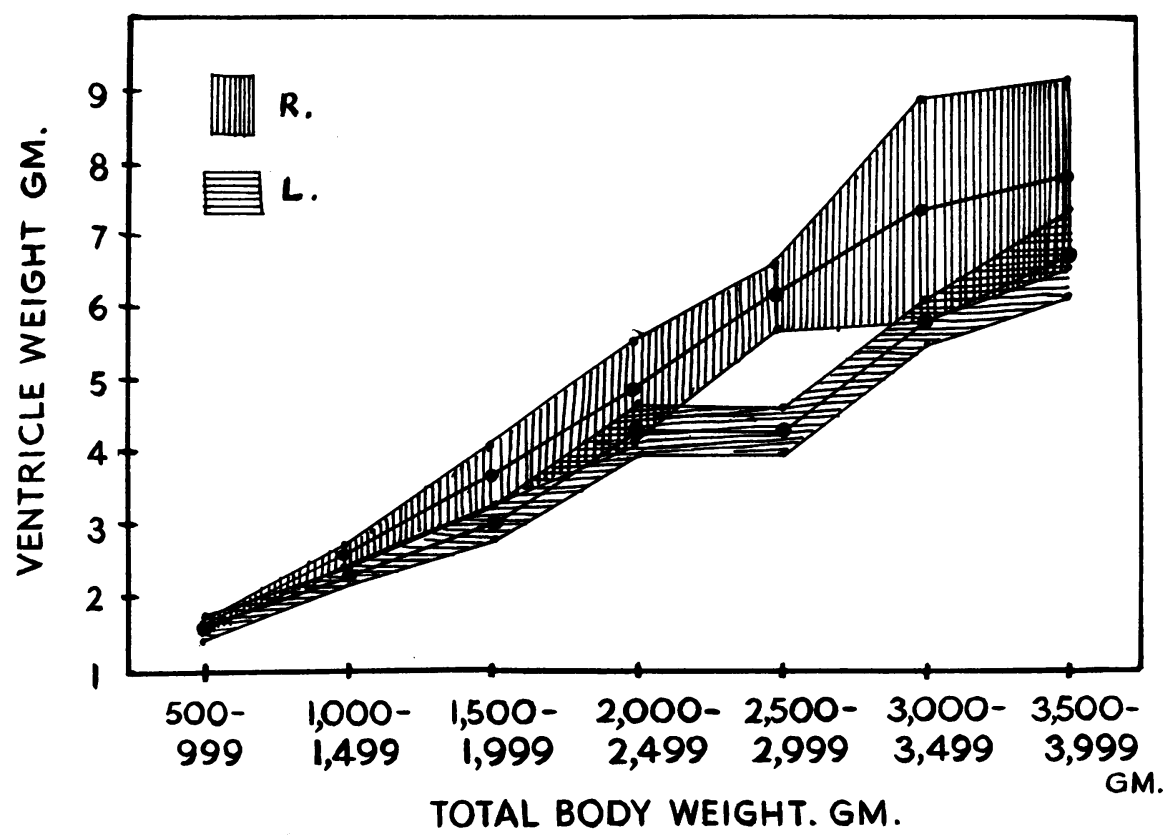

FIG. 6.-Graph showing the mean right and left ventricular weights with their limits of trustworthiness against body weight.

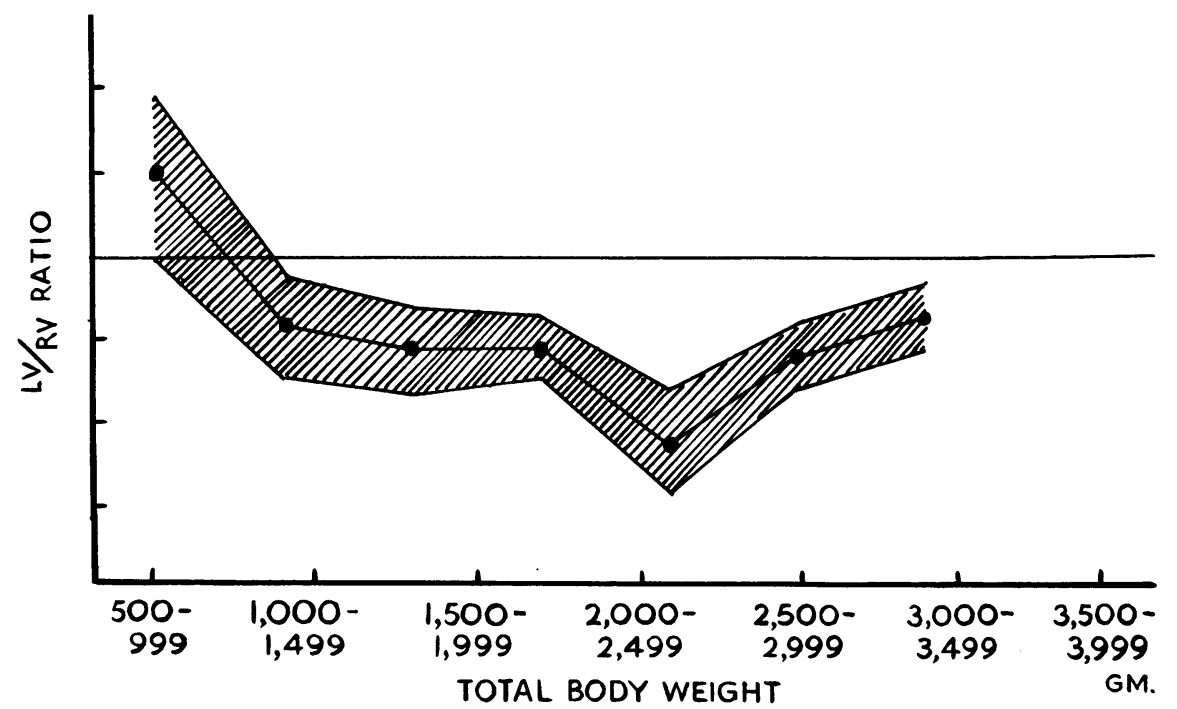

FIG. 7.-Graph showing the mean L.V./R.V. weight ratios and their limits of trustworthiness, against body weight.

L.V. $2 \cdot 3(\sigma 0 \cdot 20)$, R.V. $2 \cdot 6(\sigma 0 \cdot 45)$; 13 children of body weight $1500-1999$ g., L.V. $3.0(\sigma 0 \cdot 71)$, R.V. 3.7 ( $\sigma 1 \cdot 1)$; 13 children of body weight 2000-2499 g., L.V. 4.3 ( $\sigma$ 1.12), R.V. 4.9 ( $\sigma$ 1.95); 9 children of body weight 2500-2999 g., L.V. $4.3(\sigma 0 \cdot 79)$, R.V. 6.2 ( $\sigma 1 \cdot 14) ; 15$ children of body weight 3000-3499 g., L.V. 5.9 ( $\sigma$ 1.0), R.V. 7.4 ( $\sigma$ 4.51); and 5 children of body weight 3500-3999 g., L.V. $6 \cdot 8(\sigma$ 1.05), R.V. $7.9(\sigma 2 \cdot 15)$.

The average weights (Fig. 6) of the two ventricles are almost equal in the infants of from 500 to $999 \mathrm{~g}$. Over this weight the right ventricle shows the greater increase in weight until in infants of 
$3000-3499 \mathrm{~g}$. its average weight is $7 \cdot 4 \mathrm{~g}$. Between this group and the final one the mean value for the right ventricle shows a slight diminution in weight gain, but the significance of this cannot be proved within the wide limits of trustworthiness of this mean and the one preceding it.

The left ventricle weight shows an irregular gain with relatively narrow limits of trustworthiness. The left ventricular weight is consistently lower than the right and in infants of $3500-4000 \mathrm{~g}$. it has reached only $6 \cdot 8 \mathrm{~g}$.

The L.V./R.V. weight ratio (Fig. 7) shows again the high ratio in the least mature infants $(1 \cdot 13)$ falling below unity to reach 0.89 in the infants of $1000-1499 \mathrm{~g}$. It then levels off and there is a slight rise to 0.9 in the heaviest group of infants.

\section{Discussion}

In the material presented here, using one population, we have shown different growth curves with different criteria of measurement of the whole child. This is due to the same infants falling into different groups in different analyses. Thus these curves are not directly comparable, but any feature common to them all has much greater significance.

Absolute Weights. The analysis by gestation age shows little difference in the weight gain with wide overlap of the limits of trustworthiness of the two curves until the 35-weeks stage. From then onwards the right ventricle gains weight more rapidly than the left, though it shows a slight deceleration between the last two groups. In this analysis the left ventricle is slightly the heavier until the age of 27 weeks, when the two weights become equal and then from 31 weeks onwards the right ventricle is increasingly the heavier.

The crown-rump length analysis shows an equal increase in weight of the two ventricles between the first two crown-rump length of $29 \mathrm{~cm}$. Thereafter the two weight curves diverge and though both show continuous increase of weight, that of the right ventricle is the greater.

In the body weight analysis the curves show the same general pattern. There is equality of right and left ventricular weight in the least mature infants, followed by more rapid right ventricular gain and then a slight deceleration of weight gain by this ventricle in the most mature infants.

L.V.|R.V. Weight Ratios. In each of the analyses the mean L.V./R.V. ratios in the least mature infants are greater than one. In two of them the lower limit of trustworthiness of the mean falls just below unity, and in the other it is well above. This indicates that in fotuses of gestation age under 32 weeks, crown-rump length less than $25 \mathrm{~cm}$. and body weight less than $1000 \mathrm{~g}$. the ventricles are about equal in weight, but with a strong probability that the left ventricle is the heavier.

All three analyses show that soon after these levels of development have been achieved there is a rapid reversal of the ratio to less than one. After the initially rapid fall there is a flattening of the mean ratio curve.

In two of the three analyses a reversal in the direction of the mean ratio curve occurs in the most mature infants so that it again begins to approach unity, anticipating the post-natal reversion. This is an extremely interesting finding which could have an important bearing on the hazards of so-called "post-maturity". In this series of stillborn infants the terminal rise in the ratio cannot be proved significant within the calculated limits of trustworthiness of the means. It seemed possible that an addition to the number of cases in each group might increase the trend if it was significant. To achieve larger numbers, data from 40 live born infants who had died within the first twenty-four hours of birth were included in the two most mature groups in each of the three analyses.

The results of increasing the numbers in these two groups was that in the gestation-age analysis the rise in the ratio between the two most mature groups was exaggerated and became significant within the calculated limits of trustworthiness. In the body weight analysis the upward trend increased a little but not sufficiently for proof of its significance. In the crown-rump length group the downward trend continued and slightly increased. The effect of adding to the number of cases in each group by this means was to increase the trends already found in the stillborn fœtuses. 


\section{SUMMARY}

At a stage of maturity that corresponds with 24-28 weeks gestation, a crown-rump length of 20-25 cm., and a body weight of 500-1000 g., the two heart ventricles are of roughly equal weight. Prior to this time the left ventricle is usually heavier than the right. Thereafter, the more rapid right ventricular gain in weight that has already been described by a number of workers is confirmed. In children of over 39 weeks gestation and $3000 \mathrm{~g}$. a reversal of the right ventricular preponderance seems to commence. This may be a physiological anticipation of the post-natal reversion to left ventricular preponderance or an indication of post maturity.

We have pleasure in acknowledging the statistical guidance of Dr. G. Jowett, head of the Department of Statistics, University of Sheffield. Dr. M. S. Macdonald was working under a grant from the Medical Research Council. The photographs were taken by Mr. P. Rickus.

\section{REFERENCES}

Blackfan, K. D. (1933). Growth and Development of the Child, Part II, Anatomy and Physiology. Report of Committee of Growth and Development. Centery, N.Y., p. 271.

Brock, J. (1932). Biologische Daten für den Kinderarzt. Springer, Berlin, p. 128.

Dull, Marianne (1940-41). Beitrage path. Anat., 105, 237.

Hort, W. (1955). Virchows Archiv. path. Anat., 326, 458.

Keen, J. A. (1955). J. Anat., 89, 484.

Latimer, H. B. (1953). Anat. Rec., 117, 713.

Merkel, H., and Witt, H. (1955). Bietrag path. Anat., 115, 178.

Muller, W. (1883). Die Massenverhaltnisse des Menschlichen Herzens. Leopold Voss, Hamburn und Leipzig.

Pansinello, F. S., Castellanos, A., Junco, J. A., and Valladares, F. (1958). Revista Cubana Pediat. 30, 19-50.

Smith, H. L. (1928-29). Amer. Heart J., 4, 79. 